\title{
The Reason Analysis and Countermeasures of Civil Engineering Costs out of Control
}

\author{
Wei Zhou \\ Wuhan Huaxia University of Technology, Institute of Civil and Building Engineering, Engineering \\ Management, Wuhan 430223 China
}

Keywords: civil engineering; cost management; cost out of control; reason analysis; cost control.

\begin{abstract}
The rapid growth of social economy has brought the fast development of construction field that will refer to lots of civil constructions. While the cost management is the vital part and it will directly affect the whole benefit of the project. However, affected by various factors, the construction costs will be out of control if not been controlled and the benefit cannot be guaranteed. Therefore, it is necessary to analyze the reason out of control and adopt the corresponding countermeasures.
\end{abstract}

\section{Introduction}

Under the current market economy, construction field faces the fiercer market environment, so the effective control with engineering cost contributes to the promotion of the core competitiveness of enterprises. The adoption of scientific and reasonable cost management measures can effectively control the input of engineering costs so as to ensure the economic benefit. But there exist various factors affecting the costs of civil engineering, having certain complexity. So, the civil engineering cost is easily out of control. In order to make the engineering cost controlled, cost management members should analyze the factors affecting the costs combining with the characteristics of civil engineering and adopt the scientific and effective control measures and promote the control effect of construction costs.

\section{Specificity of Civil Engineering Costs}

Civil engineering costs have certain specificity, mainly showing the enormous quantities and dynamic costs. Due to the development of economy, the civil engineering is constantly expanding the size and the amount is very huge. Besides, the invest has the sequence for the civil engineering has the long construction period and complex procedures. So, it is very necessary to implement the cost control with civil engineering. Because of the long construction period, there will exist many uncertain factors in the process, for example, the costs of civil engineering will be affected by the market environment in the scheduled construction period, such as the price change of various materials, human fees and machine fees. So, the engineering cost is in the dynamic change, and the real cost can be explicit only after the whole completion. So, the civil engineering cost is fluctuated and dynamic.

\section{The Necessity of Civil Engineering Costs}

\subsection{Contents of Civil Engineering Costs Control}

Civil engineering cost means all the fees produced by the reproduction of various tangible assets and intangible assets input. In the civil engineering, cost control means the control behavior through technological and economic methods with all the parts and projects in the construction period. The cost control of civil engineering is manifested in the ability of forecast and analysis.

\subsection{Composition Factors of Civil Engineering Costs}

The costs manly include two parts: one is the fixed-asset investment, and the other one is the current asset investment. Among them, the fee produced by the fixed asset includes the facility and 
machine purchase, installation project and engineering construction. Besides, it also includes the basic and increased budget reserve and the debt interest existing in the construction period. All these fees will take up over the eight percent of the whole cost as shown in Figure 1.

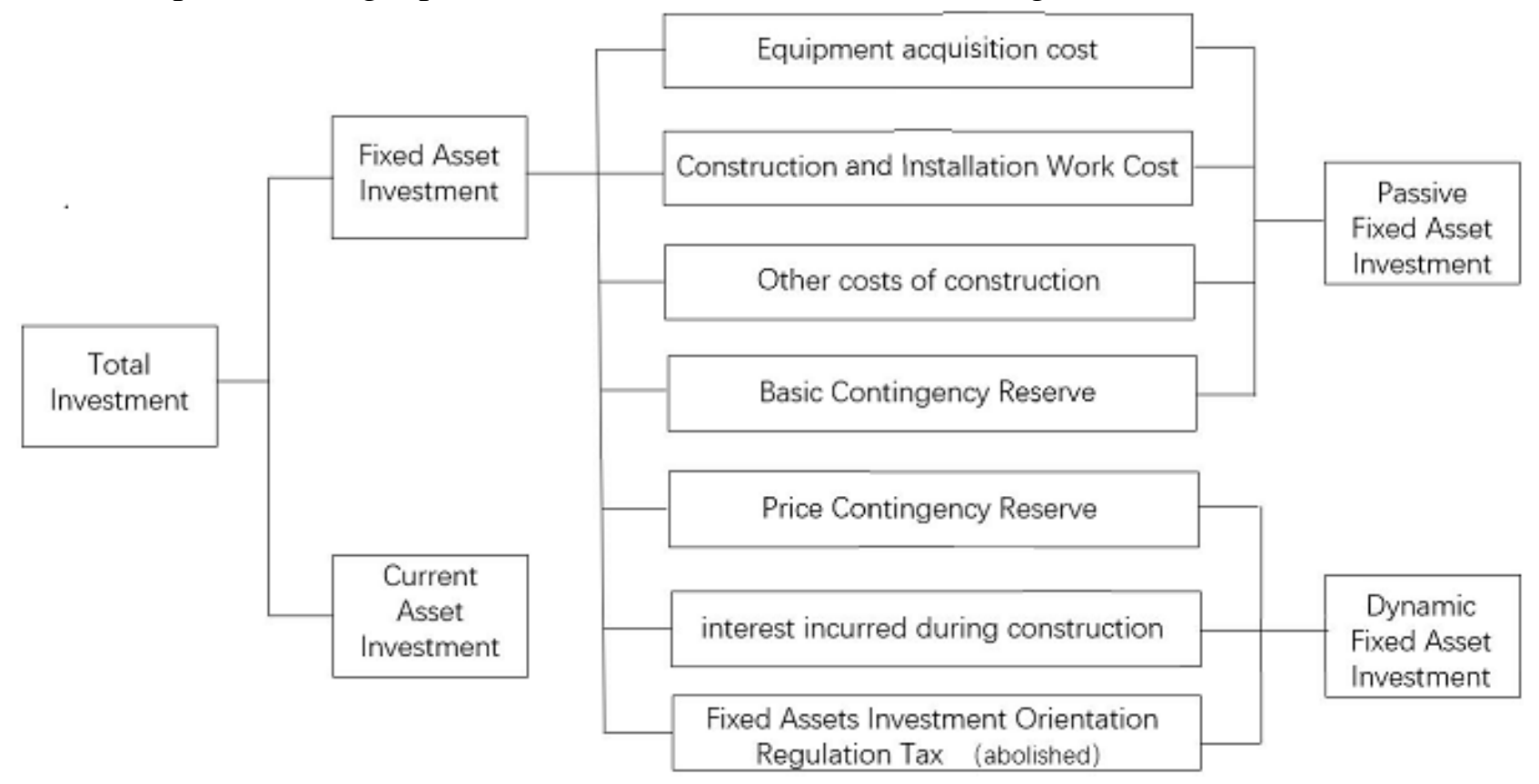

Fig. 1 Components of civil engineering costs

\subsection{Methods of Civil Engineering Implementing the Cost Control}

In the civil engineering, the costs control manifests the optimization with engineering design and management in the construction process. Because that the cost control can promote the effect of engineering design and the optimization and promotion can make the design more reasonable, achieve the accurate control of project investment and better manifest the control effect on fees of cost budget. The control effect can be better achieved. The investment control should combine the reality of construction unit and ensure the rationality of control within the affordable range. What's more, the construction unit of all the projects should pay attention to the rational arrangement of capital in the cost control of civil engineering. And all kinds of capital arrangement should combine with the characteristics of project, which contributes to the capital of construction unit gain the biggest benefit.

\section{Reason Analysis of Civil Engineering Cost Out of Control}

\subsection{The Related Members of Cost Control Have Low Quality}

Currently, there are many people majoring in the cost management, but their business qualities vary a lot. Part members lack specific professional skill training, not equipping with the cost practicing certificate admitted by the country. The professional level of members can affect the effect of cost management. Besides, part of management members occupied with the costs don't pay attention to the promotion of personal specific knowledge. The current civil engineering is rapidly developing while the knowledge structure of part cost members has lag, so the cost control of civil engineering lacks the corresponding ability. The control effect of engineering cost is so bad that cannot satisfy the rapid development demand of civil engineering.

\subsection{Engineering Change}

Engineering changes usually occur in the construction process of civil engineering, which will affect the cost control. So, engineering design members should focus on promoting the design level and reducing the production of change. The corresponding measures should be adopted in the construction to ensure the effect of engineering cost control if the design changes occur. Part of 
members lack the necessary check with the real condition of construction field when designing the engineering. So, the design plan is hard to ensure the rationality. And their will exist the difference between the real condition and design plan, influencing the engineering cost control. Constructors don't do completely according to the design plan and standard in the process and privately alter the plan that will also exert an effect on the engineering cost control.

\subsection{Construction Facilities and the Influence of Materials}

Construction facilities and material price are closely related with the engineering cost, which are the main contents affecting the cost control. It is easily appeared that the cost is out of control if the construction manager lacks effective management with the construction facilities and materials. Purchasers lack the overall investigation with market condition when purchasing the materials or purchasing the rental facilities, leading to the rather great change of facilities and materials costs and effect on the cost control. Besides, lack of the scientific management with facilities will result in the bad using effect and the value of facilities cannot be given full play to. The facility is easy to broke down if it lacks the necessary maintenance and the corresponding costs will increase while the service life will reduce. As for the construction material, it takes up a rather big proportion in the civil engineering cost. If purchasers lack the market price awareness or ignore the quality of material, it will affect the effective control of costs.

\subsection{Effect of Management in the Construction Process}

Management has a direct effect on the cost control in the civil engineering. Lacking of scientific management will result in the overspending of budget. In the construction process, the overdue communication and exchange between the cost members and construction members will affect the cost control. If the constructors lack the related specific knowledge with cost management, corresponding management measures with cost control and control with construction cost, it will affect the cost control. Besides, in the field management of civil engineering, the management of construction field easily appears the chaos, affected by the size, period and procedures. It will be bound to affect the effective control with engineering cost if the manager cannot timely adjust in combination with the change condition of the construction field.

\subsection{The Influence of Engineering Completion Settlement}

In the process of cost control, the construction enterprises will usually ignore the effect of engineering settlement on the cost. In this stage, the whole cost conditions should be gathered and then the file after the settlement should be approved by the related management departments to clarify the payment, which can guarantee the overall management of engineering cost. However, due to the management reason, there exists the cost waste in the stage of engineering settlement. And there will exist the inaccurate data, unreasonable price methods and wrong fixed standards. This reflects the lack of correct awareness with engineering costs. And inaccurate settlement results in the increasing of engineering costs and affects the cost management.

\section{Countermeasures of Civil Engineering Cost out of Control}

\subsection{Strengthen the Management of Civil Engineering}

At the same time of considering the scientific and reasonable design plan, the engineering cost should be reduced as low as possible. Therefore, the design should be strengthened the management and the optimization of civil engineering is beneficial to the cost control. The supervision and management with design units can promote the design quality and help them pay attention to the scientific and reasonable design plan. The design plan will have the practicality and economy. When calling for bids, they should strictly investigate the engineering quantity list of bid files and avoid the unnecessary investment cost; choose the strong construction enterprises to construct according to the 
rule of market economy. The material consuming should be strictly controlled in the process and the effect of engineering settlement on the cost should be eliminated.

\subsection{Improve Cost Personnel's Quality}

The work level of cost personnel can directly affect the quality of engineering costs. Building the perfect construction cost management and supervision system can directly accelerate the promotion of construction cost level. Therefore, the feasible measures should be adopted to promote the professional level and skill quality of construction cost personnel. They should constantly learn new theory knowledge and conclude and explore the cost management methods. Their control methods and management concepts should constantly refresh along with the development of times to make the cost control better adapt the development of current civil engineering. The cost out of control is related to the quality of cost personnel, so their qualities should be paid attention to and they can refresh the professional knowledge and broaden the horizon to promote the cost control through the regular training.

\subsection{Improve the Supervision System}

Under the current market economy, all the economic activities of enterprises should be oriented with the market, and the benefit level of enterprises should correspond with the market development, which can guarantee the corresponding benefit space. Therefore, the supervision and management with engineering costs should obey the development rule of economy market and the supervision system catering to the market economy development, which is oriented with the development of market economy and implements the dynamic management, is supposed to be built in the construction field. The improvement of market supervision and management system can effectively give play to the adjustment role of market and promote the self-promotion of construction enterprises and strengthen the competitiveness.

\subsection{There Should Be the Cost Management Measures Before the Construction}

The related members should connect with the capital implementation to manage on schedule before the construction and formulate the effective capital usage rule. Cost members should be familiar with the design content and analyze the capital usage of projects in combination with the real contract formulating content. Arrange the capital according to the related quota standard, make it explicit that the required members, machines, facilities and related materials and ensure the input human force, facilities and material quantities feasible. Cost members should formulate the capital usage plans for all the stages and the content should meet with the target of cost control and ensure the rationality and feasibility of cost control. The computing of engineering cost should be based on the design standard of construction, current development condition of construction technology and the market price of various production elements. The engineering cost is very important in the management of construction, which should adopt the scientific method and standard pricing manner. And it directly affects the economic benefit of construction enterprises. Therefore, they should analyze the affecting factors with construction costs and adopt specific countermeasures to reduce the engineering costs.

\subsection{Pay Attention to the Cost Control in the Construction Process}

The construction is key to the civil engineering cost. In this stage, the control effect of costs will affect the costs of whole project. Due to the rather long construction period of civil engineering, material fee, human capital and machine price will appear some changes, which will have certain effect on the civil engineering costs. So, in the construction of civil engineering, the costs should be strictly controlled to avoid the effect of various unfavorable factors at the same time of guaranteeing the quality. 


\subsection{Pay Attention to the Cost Control in the Completion Settlement Stage}

The true and effective engineering costs should be made as the requisite of cost control so as to ensure the rationality of civil engineering cost and eliminate the phenomena of irrational waste, damage out of the plan and unreasonable fees. In the control of construction cost, the settlement data accuracy of civil engineering after the completion is the emphasis of achieving the construction cost. The accuracy and reliability of data should be ensured and the settlement content should be completed in the completion settlement stage. So, the information collection and arrangement in the completion stage should be paid attention to. Besides, the computing methods should be emphasized to avoid the repeated computing of engineering quantities and over-valued price of materials that will affect the true construction costs. Therefore, the accuracy of completion settlement should be guaranteed to ensure the effect of cost control.

\section{Conclusion}

In the management of civil engineering, construction costs are of great significance due to its direct relation with the economic benefit of construction enterprises. So, in order to avoid the construction costs out of control, those affected factors aiming at civil engineering costs should be analyzed and corresponding measures should be adopted.

\section{References}

[1]. Xupeng Li. The Reason Analysis and Countermeasures of Civil Engineering Costs out of Control. Jiangxi Building Materials, 2016(4):241-242.

[2]. Yulin Zhao. The Existing Problems and Solutions of Civil Engineering Costs Management. Green Building Materials, 2016(3):105

[3]. Wentao Zhao. The Dilemma and Solution of Civil Engineering Costs Management. The Southern Farm Machinery, 2016(3):256-257.

[4]. Lihua Tian. The Reasons and Control measures of construction Costs Over-budget. Engineering and Technological Research, 2016(4):107-108.

[5]. Wei Li, Ping Yang. The Existing Problems and Solutions of Civil Engineering Costs Management. Residence and Real Estate, 2016(9):134.

[6]. Xianxing Zhang, Lidan Zhang. The Construction Costs Control Research based on the Engineering Budget. Engineering and Technological Research, 2017(4):170-171 